\title{
Convergence Theorems on Generalized Equilibrium Problems and Fixed Point Problems with Applications
}

\author{
Yan Hao, ${ }^{1}$ Sun Young Cho, ${ }^{2}$ and Xiaolong Qin ${ }^{3}$ \\ ${ }^{1}$ School of Mathematics, Physics and Information Science, Zhejiang Ocean University, \\ Zhoushan 316004, China \\ ${ }^{2}$ Department of Mathematics, Gyeongsang National University, Jinju 660-701, South Korea \\ ${ }^{3}$ Department of Mathematics, Hangzhou Normal University, Hangzhou 310036, China
}

Correspondence should be addressed to Yan Hao, zjhaoyan@yahoo.cn

Received 2 October 2009; Accepted 23 January 2010

Academic Editor: Jong Kim

Copyright (C) 2010 Yan Hao et al. This is an open access article distributed under the Creative Commons Attribution License, which permits unrestricted use, distribution, and reproduction in any medium, provided the original work is properly cited.

The purpose of this work is to introduce an iterative method for finding a common element of a solution set of a generalized equilibrium problem, of a solution set solutions of a variational inequality problem and of a fixed point set of a strict pseudocontraction. Strong convergence theorems are established in the framework of Hilbert spaces.

\section{Introduction and Preliminaries}

Let $H$ be a real Hilbert space, $C$ a nonempty closed and convex subset of $H$, and $B: C \rightarrow H$ a nonlinear mapping. Recall the following definitions.

(a) The mapping $B$ is said to be monotone if

$$
\langle B x-B y, x-y\rangle \geq 0, \quad \forall x, y \in C
$$

(b) $B$ is said to be $\beta$-strongly monotone if there exists a constant $\beta>0$ such that

$$
\langle B x-B y, x-y\rangle \geq \beta\|x-y\|^{2}, \quad \forall x, y \in C .
$$


(c) $B$ is said to be $\beta$-inverse-strongly monotone if there exists a constant $\beta>0$ such that

$$
\langle B x-B y, x-y\rangle \geq \beta\|B x-B y\|^{2}, \quad \forall x, y \in C .
$$

The classical variational inequality problem is to find $u \in C$ such that

$$
\langle B u, v-u\rangle \geq 0, \quad \forall v \in C
$$

In this paper, we use $\operatorname{VI}(C, B)$ to denote the solution set of the problem (1.4). One can easily see that the variational inequality problem is equivalent to a fixed point problem. $u \in C$ is a solution to the problem (1.4) if and only if $u$ is a fixed point of the mapping $P_{C}(I-\lambda B)$, where $\lambda>0$ is a constant and $I$ is the identity mapping.

Let $S: C \rightarrow C$ be a nonlinear mapping. In this paper, we use $F(S)$ to denote the fixed point set of $S$. Recall the following definitions.

(d) The mapping $S$ is said to be nonexpansive if

$$
\|S x-S y\| \leq\|x-y\|, \quad \forall x, y \in C
$$

(e) $S$ is strictly pseudocontractive with a constant $k \in[0,1)$ if

$$
\|S x-S y\|^{2} \leq\|x-y\|^{2}+k\|(I-S) x-(I-S) y\|^{2}, \quad \forall x, y \in C
$$

For such a case, $S$ is called a $k$-strict pseudocontraction.

(f) $S$ is said to be pseudocontractive if

$$
\|S x-S y\|^{2} \leq\|x-y\|^{2}+\|(I-S) x-(I-S) y\|^{2}, \quad \forall x, y \in C .
$$

Clearly, the class of strict pseudocontractions falls into the one between a class of nonexpansive mappings and a class of pseudocontractions.

Recently, many authors considered the problem of finding a common element of the solution set of the variational inequality (1.4) and of fixed point set of a nonexpansive mapping in Hilbert spaces; see, for examples, [1-5] and the references therein.

In 2005, Iiduka and Takahashi [2] obtained the following theorem in a real Hilbert space.

Theorem IT. Let $C$ be a closed convex subset of a real Hilbert space $H$. Let $B$ be an $\alpha$-inversestrongly monotone mapping of $C$ into $H$ and let $S$ be a nonexpansive mapping of $C$ into itself such that $F(S) \cap \operatorname{VI}(C, B) \neq \emptyset$. Suppose $x_{1}=x \in C$ and $\left\{x_{n}\right\}$ is given by

$$
x_{n+1}=\alpha_{n} x+\left(1-\alpha_{n}\right) S P_{C}\left(x_{n}-\lambda_{n} B x_{n}\right)
$$


for every $n=1,2, \ldots$, where $\left\{\alpha_{n}\right\}$ is a sequence in $[0,1)$ and $\left\{\lambda_{n}\right\}$ is a sequence in $[a, b]$. If $\left\{\alpha_{n}\right\}$ and $\left\{\lambda_{n}\right\}$ are chosen so that $\left\{\lambda_{n}\right\} \in[a, b]$ for some $a, b$ with $0<a<b<2 \alpha$,

$$
\lim _{n \rightarrow \infty} \alpha_{n}=0, \quad \sum_{n=1}^{\infty} \alpha_{n}=\infty, \quad \sum_{n=1}^{\infty}\left|\alpha_{n+1}-\alpha_{n}\right|<\infty, \quad \sum_{n=1}^{\infty}\left|\lambda_{n+1}-\lambda_{n}\right|<\infty,
$$

then $\left\{x_{n}\right\}$ converges strongly to $P_{F(S) \cap V I(C, B)} x$.

Let $A$ be an inverse-strongly monotone mapping, and $F$ a bifunction of $C \times C$ into $\mathbb{R}$, where $\mathbb{R}$ is the set of real numbers. We consider the following equilibrium problem:

$$
\text { find } z \in C \text { such that } F(z, y)+\langle A z, y-z\rangle \geq 0, \quad \forall y \in C
$$

In this paper, the set of such $z \in C$ is denoted by $\operatorname{EP}(F, A)$, that is,

$$
\mathrm{EP}(F, A)=\{z \in C: F(z, y)+\langle A z, y-z\rangle \geq 0, \forall y \in C\}
$$

In the case of $A \equiv 0$, the zero mapping, the problem (1.10) is reduced to

$$
\text { Find } z \in C \text { such that } F(z, y) \geq 0, \quad \forall y \in C \text {. }
$$

In this paper, we use $\mathrm{EP}(F)$ to denote the solution set of the problem (1.12), which was studied by many others; see, for examples, $[1,3,6-23]$ and the reference therein. In the case of $F \equiv 0$, the problem (1.10) is reduced to the classical variational inequality (1.4). The problem (1.10) is very general in the sense that it includes, as special cases, optimization problems, variational inequalities, minimax problems, the Nash equilibrium problem in noncooperative games, and others; see, for instances, $[15,24]$.

To study the problems (1.10) and (1.12), we may assume that the bifunction $F: C \times$ $C \rightarrow \mathbb{R}$ satisfies the following conditions:

(A1) $F(x, x)=0$ for all $x \in C$;

(A2) $F$ is monotone, that is, $F(x, y)+F(y, x) \leq 0$ for all $x, y \in C$;

(A3) for each $x, y, z \in C$,

$$
\limsup _{t \downarrow 0} F(t z+(1-t) x, y) \leq F(x, y)
$$

(A4) for each $x \in C, y \mapsto F(x, y)$ is convex and weakly lower semicontinuous.

Recently, S. Takahashi and W. Takahashi [21] considered the problem (1.12) by introducing an iterative method in a Hilbert space. To be more precise, they proved the following theorem. 
Theorem TT 1. Let $C$ be a nonempty closed convex subset of $H$. Let $F$ be a bifunction from $C \times C$ to $\mathbb{R}$ satisfying (A1)-(A4), and let $S$ be a nonexpansive mapping of $C$ into $H$ such that $F(S) \cap E P(F) \neq \emptyset$. Let $f$ be a contraction of $H$ into itself, and let $\left\{x_{n}\right\}$ and $\left\{y_{n}\right\}$ be sequences generated by $x_{1} \in H$ and

$$
\begin{gathered}
F\left(y_{n}, u\right)+\frac{1}{r_{n}}\left\langle u-y_{n}, y_{n}-x_{n}\right\rangle \geq 0, \quad \forall u \in C, \\
x_{n+1}=\alpha_{n} f\left(x_{n}\right)+\left(1-\alpha_{n}\right) S y_{n}, \quad n \geq 1,
\end{gathered}
$$

where $\left\{\alpha_{n}\right\} \in[0,1]$ and $\left\{r_{n}\right\} \subset(0, \infty)$ satisfy

$$
\begin{gathered}
\lim _{n \rightarrow \infty} \alpha_{n}=0, \quad \sum_{n=1}^{\infty} \alpha_{n}=\infty, \quad \sum_{n=1}^{\infty}\left|\alpha_{n+1}-\alpha_{n}\right|<\infty, \\
\liminf _{n \rightarrow \infty} r_{n}>0, \quad \sum_{n=1}^{\infty}\left|r_{n+1}-r_{n}\right|<\infty .
\end{gathered}
$$

Then $\left\{x_{n}\right\}$ and $\left\{y_{n}\right\}$ converge strongly to $z \in F(S) \cap \operatorname{EP}(F)$, where $z=P_{F(S) \cap \operatorname{EP}(F)} f(z)$.

Very recently, S. Takahashi and W. Takahashi [22] further considered the problem (1.10). Strong convergence theorems of common elements are established. More precisely, they obtained the following result.

Theorem TT 2. Let $C$ be a closed convex subset of a real Hilbert space $H$, and let $F: C \times C \rightarrow \mathbb{R}$ be a bifunction satisfying (A1), (A2), (A3) and (A4). Let $A$ be an $\alpha$-inverse-strongly monotone mapping of $C$ into $H$ and let $S$ be a nonexpansive mapping of $C$ into itself such that $F(S) \cap \operatorname{EP}(F, A) \neq \emptyset$. Let $u \in C$ and $x_{1} \in C$ and let $\left\{z_{n}\right\} \subset C$ and $\left\{x_{n}\right\} \subset C$ be sequences generated by

$$
\begin{gathered}
F\left(z_{n}, y\right)+\left\langle A x_{n}, y-z_{n}\right\rangle+\frac{1}{\lambda_{n}}\left\langle y-z_{n}, z_{n}-x_{n}\right\rangle \geq 0, \quad \forall y \in C, \\
x_{n+1}=\beta_{n} x_{n}+\left(1-\beta_{n}\right) S\left[\alpha_{n} u+\left(1-\alpha_{n}\right) z_{n}\right], \quad \forall n \geq 1,
\end{gathered}
$$

where $\left\{\alpha_{n}\right\} \subset[0,1],\left\{\beta_{n}\right\} \subset[0,1]$, and $\left\{\lambda_{n}\right\} \subset[0,2 \alpha]$ satisfy

$$
\begin{gathered}
0<c \leq \beta_{n} \leq d<1, \quad 0<a \leq \lambda_{n} \leq b<2 \alpha, \\
\lim _{n \rightarrow \infty}\left(\lambda_{n}-\lambda_{n+1}\right)=0, \quad \lim _{n \rightarrow \infty} \alpha_{n}=0, \quad \sum_{n=1}^{\infty} \alpha_{n}=\infty .
\end{gathered}
$$

Then, $\left\{x_{n}\right\}$ converges strongly to $z=P_{F(S) \cap E P(F, A)} u$.

In this paper, motivated by Theorem IT, Theorem TT1, and Theorem TT2, we introduce a general iterative method for the problem of finding a common element of a solution set of a generalized equilibrium problem (1.10), of a solution set of a variational inequality problem (1.4), and of a fixed point set of a strict pseudocontraction. Strong convergence theorems are established in the framework of Hilbert spaces. The results presented in this paper improve and extend the corresponding results announced by many others. 
In order to prove our main results, we need the following lemmas.

The following lemmas can be found in [11, 24].

Lemma 1.1. Let $C$ be a nonempty closed convex subset of $H$ and let $F: C \times C \rightarrow \mathbb{R}$ be a bifunction satisfying (A1)-(A4). Then, for any $r>0$ and $x \in H$, there exists $z \in C$ such that

$$
F(z, y)+\frac{1}{r}\langle y-z, z-x\rangle \geq 0, \quad \forall y \in C .
$$

Further, define a mapping $T_{r}$ by

$$
T_{r} x=\left\{z \in C: F(z, y)+\frac{1}{r}\langle y-z, z-x\rangle \geq 0, \forall y \in C\right\}
$$

for all $r>0$ and $x \in H$. Then, the following hold.

(1) $T_{r}$ is single-valued;

(2) $T_{r}$ is firmly nonexpansive, that is, for any $x, y \in H$,

$$
\left\|T_{r} x-T_{r} y\right\|^{2} \leq\left\langle T_{r} x-T_{r} y, x-y\right\rangle
$$

(3) $F\left(T_{r}\right)=\mathrm{EP}(F)$;

(4) $\mathrm{EP}(F)$ is closed and convex.

Lemma 1.2 (see [25]). Let $C$ be a nonempty closed convex subset of a real Hilbert space $H$ and $S: C \rightarrow C$ a k-strict pseudocontraction. Define $S_{\alpha}: C \rightarrow C$ by $S_{\alpha} x=\alpha x+(1-\alpha) S x$ for each $x \in C$. Then, as $\alpha \in[k, 1), S_{\alpha}$ is nonexpansive and $F\left(S_{\alpha}\right)=F(S)$.

Lemma 1.3 (see [26]). Let $\left\{x_{n}\right\}$ and $\left\{y_{n}\right\}$ be bounded sequences in a Banach space $X$ and let $\left\{\beta_{n}\right\}$ be a sequence in $[0,1]$ with

$$
0<\liminf _{n \rightarrow \infty} \beta_{n} \leq \limsup _{n \rightarrow \infty} \beta_{n}<1
$$

Suppose that $x_{n+1}=\left(1-\beta_{n}\right) y_{n}+\beta_{n} x_{n}$ for all integers $n \geq 0$ and

$$
\limsup _{n \rightarrow \infty}\left(\left\|y_{n+1}-y_{n}\right\|-\left\|x_{n+1}-x_{n}\right\|\right) \leq 0 .
$$

Then $\lim _{n \rightarrow \infty}\left\|y_{n}-x_{n}\right\|=0$.

The following lemma can be deduced from Bruck [8].

Lemma 1.4. Let $C$ be a closed convex subset of a strictly convex Banach space E. Let $S_{1}, S_{2}$, and $S_{3}$ be three nonexpansive mappings on $C$. Suppose $\bigcap_{n=1}^{3} F\left(S_{n}\right)$ is nonempty. Let $a_{1}, a_{2}$, and $a_{3}$ be three constant in $(0,1)$. Then the mapping $S$ on $C$ defined by

$$
S x=a_{1} S_{1} x+a_{2} S_{2} x+a_{3} S_{3} x
$$

for $x \in C$ is well defined, nonexpansive, and $F(S)=\bigcap_{n=1}^{3} F\left(S_{n}\right)$ holds. 
Lemma 1.5 (see [6]). Let $H$ be a real Hilbert space, $C$ a nonempty closed and convex subset of $E$, and $S: C \rightarrow C$ a nonexpansive mapping. Then $I-S$ is demiclosed at zero.

Lemma 1.6 (see [14]). Let $H$ be a real Hilbert space, $C$ a nonempty closed and convex subset of $E$ and $S: C \rightarrow C$ a $k$-strict pseudocontraction. Then $F(S)$ is closed and convex.

Lemma 1.7 (see [27]). Assume that $\left\{\alpha_{n}\right\}$ is a sequence of nonnegative real numbers such that

$$
\alpha_{n+1} \leq\left(1-\gamma_{n}\right) \alpha_{n}+\delta_{n}
$$

where $\left\{\gamma_{n}\right\}$ is a sequence in $(0,1)$ and $\left\{\delta_{n}\right\}$ is a sequence such that

(a) $\sum_{n=1}^{\infty} \gamma_{n}=\infty$;

(b) $\lim \sup _{n \rightarrow \infty} \delta_{n} / \gamma_{n} \leq 0$ or $\sum_{n=1}^{\infty}\left|\delta_{n}\right|<\infty$.

Then $\lim _{n \rightarrow \infty} \alpha_{n}=0$.

\section{Main Results}

Theorem 2.1. Let $C$ be a nonempty closed and convex subset of a real Hilbert space $H$ and $F$ a bifunction from $C \times C$ to $\mathbb{R}$ satisfying (A1)-(A4). Let $A$ be an $\alpha$-inverse-strongly monotone mapping of $C$ into $H$ and $B$ a $\beta$-inverse-strongly monotone mapping of $C$ into $H$. Let $S: C \rightarrow C$ be a $k$-strict pseudocontraction with a fixed point. Assume that $\Omega:=\mathrm{EP}(F, A) \cap F(S) \cap \operatorname{VI}(C, B) \neq \emptyset$. Let $\left\{x_{n}\right\}$ be a sequence in $C$ generated by

$$
\begin{gathered}
x_{1} \in C, \quad \text { chosen arbitrarily, } \\
F\left(u_{n}, y\right)+\left\langle A x_{n}, y-u_{n}\right\rangle+\frac{1}{r}\left\langle y-u_{n}, u_{n}-x_{n}\right\rangle \geq 0, \quad \forall y \in C, \\
v_{n}=P_{C}\left(x_{n}-\lambda B x_{n}\right), \\
y_{n}=\delta_{n} x_{n}+\left(1-\delta_{n}\right) S x_{n}, \\
x_{n+1}=\alpha_{n} u+\beta_{n} x_{n}+\gamma_{n}\left(\mu_{(1, n)} y_{n}+\mu_{(2, n)} u_{n}+\mu_{(3, n)} v_{n}\right), \quad \forall n \geq 1,
\end{gathered}
$$

where $u$ is a fixed element in $C,\left\{\alpha_{n}\right\},\left\{\beta_{n}\right\},\left\{\gamma_{n}\right\},\left\{\mu_{(1, n)}\right\},\left\{\mu_{(2, n)}\right\}$ and $\left\{\mu_{(3, n)}\right\}$ are sequences in $(0,1)$, $\left\{\delta_{n}\right\}$ is sequence in $[k, 1), r \in(0,2 \alpha]$ and $\lambda \in(0,2 \beta]$. Assume that the above control sequences satisfy the following restrictions

(R1) $\alpha_{n}+\beta_{n}+\gamma_{n}=\mu_{(1, n)}+\mu_{(2, n)}+\mu_{(3, n)}=1$, for all $n \geq 1$;

(R2) $\lim _{n \rightarrow \infty} \alpha_{n}=0, \sum_{n=1}^{\infty} \alpha_{n}=\infty$;

(R3) $0<\liminf _{n \rightarrow \infty} \beta_{n} \leq \lim \sup _{n \rightarrow \infty} \beta_{n}<1$;

(R4) $\lim _{n \rightarrow \infty} \delta_{n}=\delta \in[k, 1)$ and $\lim _{n \rightarrow \infty} \mu_{(i, n)}=\mu_{i} \in(0,1)$ for all $1 \leq i \leq 3$.

Then the sequence $\left\{x_{n}\right\}$ defined by the iterative process (2.1) converges strongly to $\bar{x}=P_{\Omega} u$.

Proof. The proof is divided into six steps.

Step 1. Show that $P_{\Omega} u$ is well defined. 
From Lemma 1.6, we see that $F(S)$ is closed and convex. On the other hand, we see that the mapping $I-r A$, where $r \in(0,2 \alpha]$, is nonexpansive. Indeed, for any $x, y \in C$, we have that

$$
\begin{aligned}
\|(I-r A) x-(I-r A) y\|^{2} & =\|x-y-r(A x-A y)\|^{2} \\
& =\|x-y\|^{2}-2 r\langle x-y, A x-A y\rangle+r^{2}\|A x-A y\|^{2} \\
& \leq\|x-y\|^{2}-2 r \alpha\|A x-A y\|^{2}+r^{2}\|A x-A y\|^{2} \\
& =\|x-y\|^{2}-r(2 \alpha-r)\|A x-A y\|^{2} \\
& \leq\|x-y\|^{2} .
\end{aligned}
$$

This shows that $I-r A$ is nonexpansive mapping. Similarly, we can prove that $I-\lambda B$, where $\lambda \in(0,2 \beta]$ is nonexpansive. It follows that $\operatorname{VI}(C, B)=F\left(P_{C}(I-\lambda B)\right)$, for all $\lambda>0$ is closed and convex. From Lemma 1.1, we see that $\operatorname{EP}(F, A)=F\left(T_{r}(I-r A)\right)$. Since $T_{r}(I-r A)$ is nonexpansive, we obtain that $\operatorname{EP}(F, A)$ is closed and convex. This shows that $P_{\Omega} u$ is well defined.

Step 2. Show that $\left\{x_{n}\right\}$ is bounded.

Put $T_{n}=\delta_{n} I+\left(1-\delta_{n}\right) S$ for each $n \geq 1$. In view of Lemma 1.2 and (R4), we obtain that $T_{n}$ is nonexpansive and $F\left(T_{n}\right)=F(S)$. Letting $x^{*} \in \Omega$, we obtain that

$$
x^{*}=T_{r}(I-r A) x^{*}=T_{n} x^{*}=S x^{*}=P_{C}(I-\lambda B) x^{*}, \quad \forall n \geq 1 .
$$

Note that $y_{n}=T_{n} x_{n}$ for each $n \geq 1$. It follows that $\left\|y_{n}-x^{*}\right\| \leq\left\|x_{n}-x^{*}\right\|$. Putting

$$
e_{n}=\mu_{(1, n)} y_{n}+\mu_{(2, n)} u_{n}+\mu_{(3, n)} v_{n}, \quad \forall n \geq 1,
$$

we have that

$$
\begin{aligned}
\left\|e_{n}-x^{*}\right\| \leq & \mu_{(1, n)}\left\|y_{n}-x^{*}\right\|+\mu_{(2, n)}\left\|u_{n}-x^{*}\right\|+\mu_{(3, n)}\left\|v_{n}-x^{*}\right\| \\
= & \mu_{(1, n)}\left\|y_{n}-x^{*}\right\|+\mu_{(2, n)}\left\|T_{r}(I-r A) x_{n}-T_{r}(I-r A) x^{*}\right\| \\
& +\mu_{(3, n)}\left\|P_{C}(I-\lambda A) x_{n}-P_{C}(I-\lambda B) x^{*}\right\| \\
\leq & \mu_{(1, n)}\left\|x_{n}-x^{*}\right\|+\mu_{(2, n)}\left\|x_{n}-x^{*}\right\|+\mu_{(3, n)}\left\|x_{n}-x^{*}\right\| \\
= & \left\|x_{n}-x^{*}\right\| .
\end{aligned}
$$


It follows that

$$
\begin{aligned}
\left\|x_{n+1}-x^{*}\right\| & =\left\|\alpha_{n} u+\beta_{n} x_{n}+\gamma_{n} e_{n}-x^{*}\right\| \\
& \leq \alpha_{n}\left\|u-x^{*}\right\|+\beta_{n}\left\|x_{n}-x^{*}\right\|+\gamma_{n}\left\|e_{n}-x^{*}\right\| \\
& \leq \alpha_{n}\left\|u-x^{*}\right\|+\beta_{n}\left\|x_{n}-x^{*}\right\|+\gamma_{n}\left\|x_{n}-x^{*}\right\| \\
& =\alpha_{n}\left\|u-x^{*}\right\|+\left(1-\alpha_{n}\right)\left\|x_{n}-x^{*}\right\| \\
& \leq \max \left\{\left\|u-x^{*}\right\|,\left\|x_{1}-x^{*}\right\|\right\} .
\end{aligned}
$$

This shows that the sequence $\left\{x_{n}\right\}$ is bounded. Note that

$$
\begin{gathered}
\left\|u_{n}-x^{*}\right\|=\left\|T_{r}(I-r A) x_{n}-x^{*}\right\| \leq\left\|x_{n}-x^{*}\right\|, \\
\left\|v_{n}-x^{*}\right\|=\left\|P_{C}\left(x_{n}-\lambda B x_{n}\right)-x^{*}\right\| \leq\left\|x_{n}-x^{*}\right\| .
\end{gathered}
$$

This proves that the sequences $\left\{u_{n}\right\}$ and $\left\{v_{n}\right\}$ are bounded, too.

Step 3. Show that $x_{n+1}-x_{n} \rightarrow 0$ as $n \rightarrow \infty$.

Note that

$$
\begin{aligned}
\left\|y_{n+1}-y_{n}\right\| & =\left\|T_{n+1} x_{n+1}-T_{n} x_{n}\right\| \\
& \leq\left\|T_{n+1} x_{n+1}-T_{n+1} x_{n}\right\|+\left\|T_{n+1} x_{n}-T_{n} x_{n}\right\| \\
& \leq\left\|x_{n+1}-x_{n}\right\|+\left|\delta_{n+1}-\delta_{n}\right| M_{1},
\end{aligned}
$$

where $M_{1}$ is an appropriate constant such that $M_{1}=\sup _{n \geq 1}\left\{\left\|x_{n}-S x_{n}\right\|\right\}$. On the other hand, we have

$$
\begin{gathered}
\left\|v_{n+1}-v_{n}\right\|=\left\|P_{C}\left(x_{n+1}-\lambda B x_{n+1}\right)-P_{C}\left(x_{n}-\lambda B x_{n}\right)\right\| \leq\left\|x_{n+1}-x_{n}\right\|, \\
\left\|u_{n+1}-u_{n}\right\|=\left\|T_{r}(I-r A) x_{n+1}-T_{r}(I-r A) x_{n}\right\| \leq\left\|x_{n+1}-x_{n}\right\| .
\end{gathered}
$$

It follows from (2.1) and (2.9) that

$$
\begin{aligned}
\left\|e_{n+1}-e_{n}\right\|= & \| \mu_{(1,(n+1))} y_{n+1}+\mu_{(2,(n+1))} u_{n+1}+\mu_{(3,(n+1))} v_{n+1} \\
& -\left(\mu_{(1, n)} y_{n}+\mu_{(2, n)} u_{n}+\mu_{(3, n)} v_{n}\right) \| \\
\leq & \mu_{(1,(n+1))}|| y_{n+1}-y_{n}\|+\| y_{n} \|\left|\mu_{(1,(n+1))}-\mu_{(1, n)}\right| \\
& +\mu_{(2,(n+1))}|| u_{n+1}-u_{n}\|+\| u_{n} \|\left|\mu_{(2,(n+1))}-\mu_{(2, n)}\right| \\
& +\mu_{(3,(n+1))}|| v_{n+1}-v_{n}\|+\| v_{n}\left\|\left|\mu_{(3,(n+1))}-\mu_{(3, n)}\right| \leq|| x_{n+1}-x_{n}\right\| \\
& +M_{2}\left(\left|\mu_{(1,(n+1))}-\mu_{(1, n)}\right|+\left|\mu_{(2,(n+1))}-\mu_{(2, n)}\right|+\left|\mu_{(3,(n+1))}-\mu_{(3, n)}\right|+\left|\delta_{n+1}-\delta_{n}\right|\right),
\end{aligned}
$$


Journal of Inequalities and Applications

where $M_{2}$ is an appropriate constant such that

$$
M_{2} \geq \max \left\{\sup _{n \geq 1}\left\|y_{n}\right\|, \sup _{n \geq 1}\left\|u_{n}\right\|, \sup _{n \geq 1}\left\|v_{n}\right\|, M_{1}\right\} .
$$

Put $l_{n}=\left(x_{n+1}-\beta_{n} x_{n}\right) /\left(1-\beta_{n}\right)$, for each $n \geq 1$, that is,

$$
x_{n+1}=\left(1-\beta_{n}\right) l_{n}+\beta_{n} x_{n}, \quad \forall n \geq 1 .
$$

Now, we compute $\left\|l_{n+1}-l_{n}\right\|$. Notice that

$$
\begin{aligned}
l_{n+1}-l_{n} & =\frac{\alpha_{n+1} u+\gamma_{n+1} e_{n+1}}{1-\beta_{n+1}}-\frac{\alpha_{n} u+\gamma_{n} e_{n}}{1-\beta_{n}} \\
& =\frac{\alpha_{n+1}}{1-\beta_{n+1}} u+\frac{1-\beta_{n+1}-\alpha_{n+1}}{1-\beta_{n+1}} e_{n+1}-\frac{\alpha_{n}}{1-\beta_{n}} u-\frac{1-\beta_{n}-\alpha_{n}}{1-\beta_{n}} e_{n} \\
& =\frac{\alpha_{n+1}}{1-\beta_{n+1}}\left(u-e_{n+1}\right)+\frac{\alpha_{n}}{1-\beta_{n}}\left(e_{n}-u\right)+e_{n+1}-e_{n} .
\end{aligned}
$$

It follows that

$$
\left\|l_{n+1}-l_{n}\right\| \leq \frac{\alpha_{n+1}}{1-\beta_{n+1}}\left\|u-e_{n+1}\right\|+\frac{\alpha_{n}}{1-\beta_{n}}\left\|e_{n}-u\right\|+\left\|e_{n+1}-e_{n}\right\| .
$$

Substituting (2.10) into (2.14), we arrive at

$$
\begin{aligned}
& \left\|l_{n+1}-l_{n}\right\|-\left\|x_{n+1}-x_{n}\right\| \\
& \leq \quad \frac{\alpha_{n+1}}{1-\beta_{n+1}}\left\|u-e_{n+1}\right\|+\frac{\alpha_{n}}{1-\beta_{n}}\left\|e_{n}-u\right\| \\
& \quad+M_{2}\left(\left|\mu_{(1,(n+1))}-\mu_{(1, n)}\right|+\left|\mu_{(2,(n+1))}-\mu_{(2, n)}\right|+\left|\mu_{(3,(n+1))}-\mu_{(3, n)}\right|+\left|\delta_{n+1}-\delta_{n}\right|\right) .
\end{aligned}
$$

It follows from the restrictions (R2)-(R4) that

$$
\limsup _{n \rightarrow \infty}\left(\left\|l_{n+1}-l_{n}\right\|-\left\|x_{n+1}-x_{n+1}\right\|\right)<0 .
$$

From Lemma 1.3, we obtain that

$$
\lim _{n \rightarrow \infty}\left\|l_{n}-x_{n}\right\|=0
$$

From (2.12), we see that

$$
x_{n+1}-x_{n}=\left(1-\beta_{n}\right)\left(l_{n}-x_{n}\right) .
$$


In view of (2.17), we get that

$$
\lim _{n \rightarrow \infty}\left\|x_{n+1}-x_{n}\right\|=0
$$

Step 4. Show that $x_{n}-e_{n} \rightarrow 0$ as $n \rightarrow \infty$.

From the iterative process (2.1), we have

$$
\gamma_{n}\left(e_{n}-x_{n}\right)=x_{n+1}-x_{n}+\alpha_{n}\left(x_{n}-u\right) .
$$

This implies that

$$
\gamma_{n}\left\|e_{n}-x_{n}\right\| \leq\left\|x_{n+1}-x_{n}\right\|+\alpha_{n}\left\|x_{n}-u\right\| .
$$

It follows from the restrictions (R2) and (R3) that we arrive at

$$
\lim _{n \rightarrow \infty}\left\|e_{n}-x_{n}\right\|=0
$$

Step 5. Show that $\limsup _{n \rightarrow \infty}\left\langle u-\bar{x}, x_{n}-\bar{x}\right\rangle \leq 0$, where $\bar{x}=P_{\Omega} u$.

To show that, we can choose a sequence $\left\{x_{n_{i}}\right\}$ of $\left\{x_{n}\right\}$ such that

$$
\limsup _{n \rightarrow \infty}\left\langle u-\bar{x}, x_{n}-\bar{x}\right\rangle=\lim _{i \rightarrow \infty}\left\langle u-\bar{x}, x_{n_{i}}-\bar{x}\right\rangle .
$$

Since $\left\{x_{n_{i}}\right\}$ is bounded, we see that there exists a subsequence $\left\{x_{n_{i_{j}}}\right\}$ of $\left\{x_{n_{i}}\right\}$ which converges weakly to $\xi$. Without loss of generality, we may assume that $x_{n_{i}} \rightarrow \xi$.

Next, we show that $\xi \in \Omega=F(S) \cap \operatorname{VI}(C, B) \cap \mathrm{EP}(F, A)$. In fact, define a mapping $Q: C \rightarrow C$ by

$$
Q x=\mu_{1} T x+\mu_{2} T_{r}(I-r A) x+\mu_{3} P_{C}(I-\lambda B), \quad \forall x \in C,
$$

where $T=\delta I+(1-\delta) S$. Note that $T$ is nonexpansive and $F(T)=F(S)$. From Lemma 1.4, we see that $Q$ is a nonexpansive mapping such that

$$
F(Q)=F(T) \cap F\left(T_{r}(I-r A)\right) \cap F\left(P_{C}(I-\lambda B)\right)=F(S) \cap \operatorname{EP}(F, A) \cap \operatorname{VI}(C, B) .
$$

On the other hand, we have

$$
\begin{aligned}
\left\|e_{n}-Q x_{n}\right\|= & \|\left(\mu_{(1, n)} y_{n}+\mu_{(2, n)} T_{r}(I-r A) x_{n}+\mu_{(3, n)} P_{C}(I-\lambda B) x_{n}\right) \\
& -\left(\mu_{1} T x_{n}+\mu_{2} T_{r}(I-r A) x_{n}+\mu_{3} P_{C}(I-\lambda B) x_{n}\right) \| \\
\leq & \left|\mu_{(1, n)} \delta_{n}-\mu_{1} \delta\right|\left\|x_{n}\right\|+\left|\mu_{(1, n)}\left(1-\delta_{n}\right)-\mu_{1}(1-\delta)\right|\left\|S x_{n}\right\| \\
& +\left\|T_{r}(I-r A) x_{n}\right\|\left|\mu_{(2, n)}-\mu_{2}\right|+\left|\mu_{(3, n)}-\mu_{3}\right|\left\|P_{C}(I-\lambda B) x_{n}\right\| .
\end{aligned}
$$


Journal of Inequalities and Applications

It follows from the condition (R4) that $e_{n}-Q x_{n} \rightarrow 0$. Note that

$$
Q x_{n}-x_{n}=Q x_{n}-e_{n}+e_{n}-x_{n} \text {. }
$$

From (2.22), we arrive at

$$
\lim _{n \rightarrow \infty}\left\|Q x_{n}-x_{n}\right\|=0
$$

It follows from Lemma 1.5 that

$$
\xi \in F(Q)=\Omega .
$$

Thanks to (2.23), we arrive at

$$
\limsup _{n \rightarrow \infty}\left\langle u-\bar{x}, x_{n}-\bar{x}\right\rangle=\langle u-\bar{x}, \xi-\bar{x}\rangle \leq 0 .
$$

Step 6. Show that $x_{n} \rightarrow \bar{x}$ as $n \rightarrow \infty$.

Notice that

$$
\begin{aligned}
\left\|x_{n+1}-\bar{x}\right\|^{2} & =\left\|\alpha_{n} u+\beta_{n} x_{n}+\gamma_{n} e_{n}-\bar{x}\right\|^{2} \\
& =\left\langle\alpha_{n}(u-\bar{x})+\beta_{n}\left(x_{n}-\bar{x}\right)+\gamma_{n}\left(e_{n}-\bar{x}\right), x_{n+1}-\bar{x}\right\rangle \\
& =\alpha_{n}\left\langle u-\bar{x}, x_{n+1}-\bar{x}\right\rangle+\beta_{n}\left\langle x_{n}-\bar{x}, x_{n+1}-\bar{x}\right\rangle+\gamma_{n}\left\langle e_{n}-\bar{x}, x_{n+1}-\bar{x}\right\rangle \\
& \leq \alpha_{n}\left\langle u-\bar{x}, x_{n+1}-\bar{x}\right\rangle+\beta_{n}\left\|x_{n}-\bar{x}\right\|\left\|x_{n+1}-\bar{x}\right\|+\gamma_{n}\left\|e_{n}-\bar{x}\right\|\left\|x_{n+1}-\bar{x}\right\| \\
& \leq \alpha_{n}\left\langle u-\bar{x}, x_{n+1}-\bar{x}\right\rangle+\beta_{n}\left\|x_{n}-\bar{x}\right\|\left\|x_{n+1}-\bar{x}\right\|+\gamma_{n}\left\|x_{n}-\bar{x}\right\|\left\|x_{n+1}-\bar{x}\right\| \\
& =\left(1-\alpha_{n}\right)\left\|x_{n}-\bar{x}\right\|\left\|x_{n+1}-\bar{x}\right\|+\alpha_{n}\left\langle u-\bar{x}, x_{n+1}-\bar{x}\right\rangle \\
& \leq \frac{\left(1-\alpha_{n}\right)}{2}\left(\left\|x_{n}-\bar{x}\right\|^{2}+\left\|x_{n+1}-\bar{x}\right\|^{2}\right)+\alpha_{n}\left\langle u-\bar{x}, x_{n+1}-\bar{x}\right\rangle,
\end{aligned}
$$

which yields that

$$
\left\|x_{n+1}-\bar{x}\right\|^{2} \leq\left(1-\alpha_{n}\right)\left\|x_{n}-\bar{x}\right\|^{2}+2 \alpha_{n}\left\langle u-\bar{x}, x_{n+1}-\bar{x}\right\rangle .
$$

In view of the restrictions (R2) and (2.30), we from Lemma 1.7 can conclude the desired conclusion easily. This completes the proof.

As corollaries of Theorem 2.1, we have the following results. 
Corollary 2.2. Let $C$ be a nonempty closed and convex subset of a real Hilbert space $H$ and $F$ a bifunction from $C \times C$ to $\mathbb{R}$ satisfying (A1)-(A4). Let $B$ be a $\beta$-inverse-strongly monotone mapping of $C$ into $H$. Let $S: C \rightarrow C$ be a $k$-strict pseudocontraction with a fixed point. Assume that $\Omega:=$ $\mathrm{EP}(F) \cap F(S) \cap \operatorname{VI}(C, B) \neq \emptyset$. Let $\left\{x_{n}\right\}$ be a sequence in $C$ generated by

$$
\begin{gathered}
x_{1} \in C, \quad \text { chosen arbitrarily, } \\
F\left(u_{n}, y\right)+\frac{1}{r}\left\langle y-u_{n}, u_{n}-x_{n}\right\rangle \geq 0, \quad \forall y \in C, \\
v_{n}=P_{C}\left(x_{n}-\lambda B x_{n}\right), \\
y_{n}=\delta_{n} x_{n}+\left(1-\delta_{n}\right) S x_{n}, \\
x_{n+1}=\alpha_{n} u+\beta_{n} x_{n}+\gamma_{n}\left(\mu_{(1, n)} y_{n}+\mu_{(2, n)} u_{n}+\mu_{(3, n)} v_{n}\right), \quad \forall n \geq 1,
\end{gathered}
$$

where $u$ is a fixed element in $C,\left\{\alpha_{n}\right\},\left\{\beta_{n}\right\},\left\{\gamma_{n}\right\},\left\{\mu_{(1, n)}\right\},\left\{\mu_{(2, n)}\right\}$, and $\left\{\mu_{(3, n)}\right\}$ are sequences in $(0,1)$, $\left\{\delta_{n}\right\}$ is sequence in $[k, 1), r \in(0, \infty)$, and $\lambda \in(0,2 \beta]$. Assume that the above control sequences satisfy the following restrictions:

(R1) $\alpha_{n}+\beta_{n}+\gamma_{n}=\mu_{(1, n)}+\mu_{(2, n)}+\mu_{(3, n)}=1$, for all $n \geq 1$;

(R2) $\lim _{n \rightarrow \infty} \alpha_{n}=0, \sum_{n=1}^{\infty} \alpha_{n}=\infty$;

(R3) $0<\liminf _{n \rightarrow \infty} \beta_{n} \leq \lim \sup _{n \rightarrow \infty} \beta_{n}<1$;

(R4) $\lim _{n \rightarrow \infty} \delta_{n}=\delta \in[k, 1)$ and $\lim _{n \rightarrow \infty} \mu_{(i, n)}=\mu_{i} \in(0,1)$ for all $1 \leq i \leq 3$.

Then the sequence $\left\{x_{n}\right\}$ defined by the iterative process (2.1) converges strongly to $\bar{x}=P_{\Omega} u$.

Proof. In Theorem 2.1, put $A=0$, the zero mapping. Then for any $\alpha>0$, we see that the the following inequality holds.

$$
\langle x-y, A x-A y\rangle \geq \alpha\|A x-A y\|^{2}
$$

Then, we can obtain the desired conclusion easily from Theorem 2.1. This completes the proof.

Corollary 2.3. Let $C$ be a nonempty closed and convex subset of a real Hilbert space $H$ and $F$ a bifunction from $C \times C$ to $\mathbb{R}$ satisfying (A1)-(A4). Let $S_{A}$ be a $k_{\alpha}$-strict pseudocontraction of $C$ into $H$ and $K_{B}$ a $k_{\beta}$-strict pseudocontraction of $C$ into $H$. Let $S: C \rightarrow C$ be a $k$-strict pseudocontraction with a fixed point. Assume that $\left.\Omega:=\operatorname{EP}\left(F, I-S_{A}\right) \cap F(S) \cap F\left(S_{B}\right)\right) \neq \emptyset$. Let $\left\{x_{n}\right\}$ be a sequence in $C$ generated by

$$
\begin{gathered}
x_{1} \in C, \quad \text { chosen arbitrarily, } \\
F\left(u_{n}, y\right)+\left\langle x_{n}-S_{A} x_{n}, y-u_{n}\right\rangle+\frac{1}{r}\left\langle y-u_{n}, u_{n}-x_{n}\right\rangle \geq 0, \quad \forall y \in C, \\
v_{n}=(1-\lambda) x_{n}+\lambda S_{B} x_{n}, \\
y_{n}=\delta_{n} x_{n}+\left(1-\delta_{n}\right) S x_{n}, \\
x_{n+1}=\alpha_{n} u+\beta_{n} x_{n}+\gamma_{n}\left(\mu_{(1, n)} y_{n}+\mu_{(2, n)} u_{n}+\mu_{(3, n)} v_{n}\right), \quad \forall n \geq 1,
\end{gathered}
$$


where $u$ is a fixed element in $C,\left\{\alpha_{n}\right\},\left\{\beta_{n}\right\},\left\{\gamma_{n}\right\},\left\{\mu_{(1, n)}\right\},\left\{\mu_{(2, n)}\right\}$, and $\left\{\mu_{(3, n)}\right\}$ are sequences in $(0,1),\left\{\delta_{n}\right\}$ is sequence in $[k, 1), r \in\left(0,1-k_{\alpha}\right]$, and $\lambda \in\left(0,1-k_{\beta}\right]$. Assume that the above control sequences satisfy the following restrictions:

(R1) $\alpha_{n}+\beta_{n}+\gamma_{n}=\mu_{(1, n)}+\mu_{(2, n)}+\mu_{(3, n)}=1$, for all $n \geq 1$;

(R2) $\lim _{n \rightarrow \infty} \alpha_{n}=0, \sum_{n=1}^{\infty} \alpha_{n}=\infty$;

(R3) $0<\liminf _{n \rightarrow \infty} \beta_{n} \leq \lim \sup _{n \rightarrow \infty} \beta_{n}<1$;

(R4) $\lim _{n \rightarrow \infty} \delta_{n}=\delta \in[k, 1)$ and $\lim _{n \rightarrow \infty} \mu_{(i, n)}=\mu_{i} \in(0,1)$ for all $1 \leq i \leq 3$.

Then the sequence $\left\{x_{n}\right\}$ defined by the above iterative process converges strongly to $\bar{x}=P_{\Omega} u$.

Proof. Put $A=I-S_{A}$ and $B=I-S_{B}$. Then, we see that $A$ is $\left(\left(1-k_{\alpha}\right) / 2\right)$-inverse-strongly monotone and $B$ is $\left(\left(1-k_{\beta}\right) / 2\right)$-inverse-strongly monotone; see [7]. We have $F\left(S_{B}\right)=\operatorname{VI}(C, B)$ and

$$
P_{C}\left(x_{n}-\lambda_{n} B x_{n}\right)=\left(1-\lambda_{n}\right) x_{n}+\lambda_{n} S_{B} x_{n}
$$

It is easy to obtain the desired conclusion from Theorem 2.1.

Remark 2.4. If $f: C \rightarrow C$ is a contractive mapping and we replace $u$ by $f\left(x_{n}\right)$ in the recursion formula (2.1), we can obtain the so-called viscosity iteration method. We note that all theorems and corollaries of this paper carry over trivially to the so-called viscosity iteration method; see [28] for more details.

\section{Acknowledgment}

This project is supported by the National Natural Science Foundation of China (no. 10901140).

\section{References}

[1] S. Chang, H. W. J. Lee, and C. K. Chan, "A new method for solving equilibrium problem fixed point problem and variational inequality problem with application to optimization," Nonlinear Analysis: Theory, Methods \& Applications, vol. 70, no. 9, pp. 3307-3319, 2009.

[2] H. Iiduka and W. Takahashi, "Strong convergence theorems for nonexpansive mappings and inversestrongly monotone mappings," Nonlinear Analysis: Theory, Methods E Applications, vol. 61, no. 3, pp. 341-350, 2005.

[3] X. Qin, Y. J. Cho, and S. M. Kang, "Viscosity approximation methods for generalized equilibrium problems and fixed point problems with applications," Nonlinear Analysis: Theory, Methods $\mathcal{E}$ Applications, vol. 72, no. 1, pp. 99-112, 2010.

[4] W. Takahashi and M. Toyoda, "Weak convergence theorems for nonexpansive mappings and monotone mappings," Journal of Optimization Theory and Applications, vol. 118, no. 2, pp. 417-428, 2003.

[5] Y. Yao and J.-C. Yao, "On modified iterative method for nonexpansive mappings and monotone mappings," Applied Mathematics and Computation, vol. 186, no. 2, pp. 1551-1558, 2007.

[6] F. E. Browder, "Convergence of approximants to fixed points of nonexpansive non-linear mappings in Banach spaces," Archive for Rational Mechanics and Analysis, vol. 24, pp. 82-90, 1967.

[7] F. E. Browder and W. V. Petryshyn, "Construction of fixed points of nonlinear mappings in Hilbert space," Journal of Mathematical Analysis and Applications, vol. 20, pp. 197-228, 1967.

[8] R. E. Bruck, Jr., "Properties of fixed-point sets of nonexpansive mappings in Banach spaces," Transactions of the American Mathematical Society, vol. 179, pp. 251-262, 1973. 
[9] L.-C. Ceng, S. Al-Homidan, Q. H. Ansari, and J.-C. Yao, “An iterative scheme for equilibrium problems and fixed point problems of strict pseudo-contraction mappings," Journal of Computational and Applied Mathematics, vol. 223, no. 2, pp. 967-974, 2009.

[10] L.-C. Ceng and J.-C. Yao, "Hybrid viscosity approximation schemes for equilibrium problems and fixed point problems of infinitely many nonexpansive mappings," Applied Mathematics and Computation, vol. 198, no. 2, pp. 729-741, 2008.

[11] P. L. Combettes and S. A. Hirstoaga, "Equilibrium programming in Hilbert spaces," Journal of Nonlinear and Convex Analysis, vol. 6, no. 1, pp. 117-136, 2005.

[12] V. Colao, G. Marino, and H.-K. Xu, "An iterative method for finding common solutions of equilibrium and fixed point problems," Journal of Mathematical Analysis and Applications, vol. 344, no. 1, pp. 340 $352,2008$.

[13] C. Jaiboon, P. Kumam, and U. W. Humphries, "Weak convergence theorem by an extragradient method for variational inequality, equilibrium and fixed point problems," Bulletin of the Malaysian Mathematical Sciences Society, vol. 32, no. 2, pp. 173-185, 2009.

[14] G. Marino and H.-K. Xu, "Weak and strong convergence theorems for strict pseudo-contractions in Hilbert spaces," Journal of Mathematical Analysis and Applications, vol. 329, no. 1, pp. 336-346, 2007.

[15] A. Moudafi and M. Théra, "Proximal and dynamical approaches to equilibrium problems," in Ill-Posed Variational Problems and Regularization Techniques (Trier, 1998), vol. 477 of Lecture Notes in Economics and Mathematical Systems, pp. 187-201, Springer, Berlin, Germany, 1999.

[16] S. Plubtieng and R. Punpaeng, "A new iterative method for equilibrium problems and fixed point problems of nonexpansive mappings and monotone mappings," Applied Mathematics and Computation, vol. 197, no. 2, pp. 548-558, 2008.

[17] X. Qin, Y. J. Cho, and S. M. Kang, "Convergence theorems of common elements for equilibrium problems and fixed point problems in Banach spaces," Journal of Computational and Applied Mathematics, vol. 225, no. 1, pp. 20-30, 2009.

[18] X. Qin, M. Shang, and Y. Su, "Strong convergence of a general iterative algorithm for equilibrium problems and variational inequality problems," Mathematical and Computer Modelling, vol. 48, no. 7-8, pp. 1033-1046, 2008.

[19] X. Qin and Y. Su, "Strong convergence theorems for relatively nonexpansive mappings in a Banach space," Nonlinear Analysis: Theory, Methods E Applications, vol. 67, no. 6, pp. 1958-1965, 2007.

[20] A. Tada and W. Takahashi, "Weak and strong convergence theorems for a nonexpansive mapping and an equilibrium problem," Journal of Optimization Theory and Applications, vol. 133, no. 3, pp. 359-370, 2007.

[21] S. Takahashi and W. Takahashi, "Viscosity approximation methods for equilibrium problems and fixed point problems in Hilbert spaces," Journal of Mathematical Analysis and Applications, vol. 331, no. 1, pp. 506-515, 2007.

[22] S. Takahashi and W. Takahashi, "Strong convergence theorem for a generalized equilibrium problem and a nonexpansive mapping in a Hilbert space," Nonlinear Analysis: Theory, Methods E Applications, vol. 69, no. 3, pp. 1025-1033, 2008.

[23] W. Takahashi and K. Zembayashi, "Strong and weak convergence theorems for equilibrium problems and relatively nonexpansive mappings in Banach spaces," Nonlinear Analysis: Theory, Methods $\mathcal{E}$ Applications, vol. 70, no. 1, pp. 45-57, 2009.

[24] E. Blum and W. Oettli, "From optimization and variational inequalities to equilibrium problems," The Mathematics Student, vol. 63, no. 1-4, pp. 123-145, 1994.

[25] H. Zhou, "Convergence theorems of fixed points for $\kappa$-strict pseudo-contractions in Hilbert spaces," Nonlinear Analysis: Theory, Methods E Applications, vol. 69, no. 2, pp. 456-462, 2008.

[26] T. Suzuki, "Strong convergence of Krasnoselskii and Mann's type sequences for one-parameter nonexpansive semigroups without Bochner integrals," Journal of Mathematical Analysis and Applications, vol. 305, no. 1, pp. 227-239, 2005.

[27] H.-K. Xu, "Iterative algorithms for nonlinear operators," Journal of the London Mathematical Society, vol. 66, no. 1, pp. 240-256, 2002.

[28] T. Suzuki, "Moudafi's viscosity approximations with Meir-Keeler contractions," Journal of Mathematical Analysis and Applications, vol. 325, no. 1, pp. 342-352, 2007. 